\title{
THE CHALLENGE OF CONTEXTUALITY
}

Bernard Lategan University of Stellenbosch

\section{I}

Why the wide-spread interest in contextuality, also and especially in dealing with biblical material? Is this the latest fad every self-respecting exegete is supposed to master in order to impress his or her peers? Is it merely a short term interest, without any lasting theological or hermeneutical significance?

The concept of contextuality certainly can be pursued for the wrong reasons. It could therefore be helpful to place this specific interest against a wider backdrop. As this has been done in more detail elsewhere (cf Lategan 1993), only a very brief outline is offered here to show how contextuality forms part of a much wider and longer development in the interpretation of biblical material.

Before doing that, a working definition of what is meant by contextuality could be helpful. 'Contextuality' refers to an awareness that the actual circumstances in which a text is read and interpreted, have a direct effect on any such interpretation. A contextual approach to texts acknowledges this effect and attempts to make it part of the methodological reflection on interpretation. 'Contextuality' therefore refers not only to the phenomenon, but tries to understand and account methodologically for the way in which the situation influences our reading and interpretation of texts.

In this sense, contextuality is nothing new. It has always been an inherent dimension of interpretation. There are, however, reasons why it has now become so prominent. It forms part of a third wave in the history of interpretation, following on the wave of historicity and the wave of structuralism. Although these waves cannot be separated neatly, it is helpful to understand how the focus on the context developed.

Each of the three waves was set in motion by the discovery of an important feature of texts and their interpretation. This feature became the dominant consideration and even assumed absolutistic dimensions. Inevitably, as insights in the nature of interpretation progressed, this dominant consideration was de-absolutized and superseded by other aspects. 
II

The discovery of the historical nature of biblical texts in the wake of the Enlightenment and the Reformation had an profound and lasting effect on biblical exegesis. Although exegetes reacted differently to this challenge, the essential historicity of these texts could no longer be denied. This not only demystified the process of interpretation, but also made us think of texts in a different way - as documents created by and reflecting the interplay of historical forces.

Without going into the implications and results of historical criticism, the important thing in terms of the issue of contextuality, is that attention shifted more and more to the process of text production. The search for the original manuscript, determining the identity of the real author, cutting through layers of redaction - all formed part of a determined effort to reconstruct the situation of production as closely as possible. The motive behind this archaeological interest was the notion that the situation of origin holds the key to understanding.

The religionsgeschichtliche preoccupation with the Sitz im Leben is in actual fact the mirror image of the preoccupation by the much later development of reception theory on the social location of the reader. In the former, the context was the situation of text production, in the latter the situation of text reception. In both cases, the (actual) historical or pragmatic situation, the social forces at work, the interests of the different role players - all are seen as providing important and even vital clues for the proper understanding of the text.

It was inevitable the discovery of the historicity of the text would be pushed to its limits. But, however fundamental the historical dimension of texts might be, an unqualified historicism was bound to run into problems sooner or later. Not only did the lack of sufficient data make historical reconstruction extremely difficult and even impossible in many instances, but the issue of relativism raised by this approach has haunted biblical interpretation ever since.

On the other hand, the focus on the historical dimension of the text already placed the issue of the context squarely on the agenda, be it the area of production. It also anticipated various of the issues contextual exegesis would raise at a later stage and in a different form.

III

The second wave in the history of interpretation can be called the structuralist phase. Many influences form the background of this development and it is in itself a very complex phenomenon (cf Vorster 1982). Here we only want to point a few aspects of direct interest to contextuality. 
In many ways, structuralism is a reaction to the underlying tenets of historicism and more especially, to the importance placed on context. Structuralism can be described as a sustained attempt to de-contextualize the text, to free it from the control of the author and the confines of the situation of production. An important argument in this respect was that the text as structure can transcend the confines of time and space only if it is liberated from its situation of production. The form this liberation takes, is that of a structured arrangement of words and sentences that takes on a life of its own and is no longer controlled by the author or its historical context.

Autonomy, diachrony, paradigmatic and syntactic relations became the important aspects when dealing with texts. The underlying assumption was that texts can be understood as structures unaffected by historical circumstances. The idea that the internal arrangement of textual components is unchangeable and remains valid in all situations, became the vogue. What impressed Levi-Strauss and other exponents was exactly the universal and unchanging nature of structures, seemingly unaffected by the vicissitudes of history. The stability of the structure made a link with formal logic and even mathematical theorems possible. In the field of biblical interpretation, the advent of structuralism was marked by a reaction against etymology as a method to determine the meaning of words (James Barr), a renewed interest in De Saussure and linguistics, the practice of discourse analysis and a growing awareness of narrative and literary structures.

The importance of structure cannot be underestimated, but neither does it offer the exclusive key to understanding. The attempt to de-contextualize the text was therefore bound to fail. In fact, context is a central concept also in structuralism, albeit in a different form. The insistence on a text-immanent approach is in actual fact the insistence to regard the text as its own context. The parameters of the text form the boundaries of this context to the exclusion of other possible contexts. Intratextuality is an expression of respect for these boundaries, as only relations within these boundaries are taken into consideration when interpreting the text.

However, contrary to the intentions of structuralism, once the text is understood and treated as a context itself, it can no longer be sealed off from other contexts. Gadamer's concept of the two horizons (cf Thiselton 1980, also Frank: 1989) is on the one hand the recognition of the context of the text as one of these horizons, but on the other hand the insistence that understanding only becomes possible if this horizon in brought into a dialectical relationship with the context of the reader, as the second horizon.

The development of intertextuality as a central concept in post-modernism, implies in a different way the crossing of the borders of the context of the single text. But this development forms part of the third wave in the interpretation of biblical material. 


\section{IV}

The advent of the reader in literary theory signalled the third wave, where contextuality finally came into its own. The shift from the context of the author, to that of the text and then to that of the reader seems natural enough, but in actual fact, it forms part of a much wider and growing interest in the pragmatic effect of language (cf Lategan 1984, 1993).

Reception theory and reader response criticism made it abundantly clear to what extent the reader plays a constituent part in assigning meaning to texts. For the first time, this role became the object of intense methodological reflection. The result was a growing awareness of the context of the reader and the final acceptance of contextuality as an essential feature of the interpretation of texts.

As indicated above, the interest in the situation of reception was in a certain sense the mirror image of the interest in the situation of production. Sitz im Leben made a come-back, this time as the social location of the reader and the history of religions' interest in the historical setting became interest in the social setting of contemporary readers. In this sense, it contributed to the development of sociological exegesis (cf Kee: 1989).

The methodological impact is the important aspect of this wave. Different readers imply different readings. What up to this stage was a practical observation, became a methodological issue. How do we account methodologically for multiple readings and multiple audiences? The problem of plurality could no longer be avoided (cf Tracy 1981; 1983).

Once a plurality of readings and of audiences is accepted, it becomes possible to explore contextuality to its full, discovering both its strengths and limitations. Various contextual readings or theologies, be they black, liberationist, feminist, male, fundamentalist or of what specific interest group could be understood, appreciated and evaluated as contextual readings and in terms of a theory of plurality.

At the same time, contextual readings brought the issue of power clearly into focus. Who is the interpretive community in which the text is read - for what purpose and in whose interest? The discovery that power is wielded through reading and interpretation, forced exegetes to face up to the questions of thetorics, also in biblical texts, and to the ethics of reading as such (cf Botha 1991).

Contextuality also played a part in what may be called the democratization of interpretation, which flows directly from the opposition to the monopoly of interpretation. This comes from two opposing corners - from the demand of mass-based organizations, from the base-communities of the church in the Third World and from the venerable principle of Reformed theology, the office of the believer. In South Africa this issue has assumed even greater urgency as theology is more and more entering the public debate. Reading, 
interpreting and appropriating the Bible is no longer the exclusive domain of a privileged few.

Contextual hermeneutics was perhaps the first really to take the 'ordinary' reader seriously. The distinction between reader and the critic has been the subject of intense debate on the theoretical level (cf Fowler 1991: 27-31), but on the pragmatic level efforts to bring theology to the member in the pew is gaining momentum. The work of West (1991), who also contributes to this volume, at the Institute for the Study of the Bible in Pietermaritzburg merits special mention in this regard. At the same time, this implies that the context of orality must also be taken into account and that we cannot confine ourselves to the context of written texts only.

The plurality of audiences and readings underline the need to do theology in an ecumenical context, to create a space where these readings can interact in a dialectical, critical and creative way.

The context of the reader can, in its turn, not be absolutized. Subsequent developments in the form of deconstruction and post-modernism have made clear that even the reader does not represent a fixed point in the process of interpretation. It has forced us, however, to acknowledge and face up to the reader-mediated nature of all our pronouncements on the author, structure, audience and meaning of texts and to accept interpretation as the ongoing challenge that it will remain.

\section{BIBLIOGRAPHY}

Botha, J 1991. Reading Romans 13. Aspects of the ethics of interpretation in a controversial text. University of Stellenbosch: Unpublished DTh-thesis.

Fowler, R M 1991. Let the reader understand. Minneapolis: Fortress.

Frank, M 1989. Limits of the human control of language: dialogue as the place of difference between neostructuralism and hermeneutics, in Michelfelder, D P \& Palmer, R E (edd). Dialogue and deconstruction: The Gadamer-Derrida encounter. Albany: State Univ of New York Press, 150161.

Kee, H C 1989. Knowing the truth. A sociological approach to New Testament interpretation. Philadelphia: Fortress.

Lategan, B C 1984. Current issues in the hermeneutical debate. Neotestamentica 18, 1-14.

Lategan, B C 1993. Aspects of a contextual hermeneutics for South Africa, in Mouton, J et al (edd). The relevance of theology for the 1990's. Pretoria: HRSC Methodology Series (forthcoming).

Thiselton. A C 1980. The two horizons. Exeter: Paternoster. 
Tracy, D 1981. The analogical imagination. Christian theology and the culture of pluralism. New York: Crossroad.

Tracy, D 1983. On thinking with the classics. Criterion 22, 9-10.

Vorster, W S 1982. De structuuranalyse, in Klijn, A F J (red). Inleiding tot de studie van het Nieuwe Testament. Kampen: Kok, 127-152.

West, G 1991. Biblical hermeneutics of liberation. Pietermaritzburg: Cluster Publications. 